\title{
Inventory Management Models in Supply Chain and Students Learning Approach
}

\author{
Aurelija Burinskienè \\ Vilnius Gediminas Technical University, Business Management Faculty, Sauletekio \\ 11, Vilnius, Lithuania \\ aurelija.burinskiene@vgtu.lt
}

\begin{abstract}
There are a lot of inventory management models. Some of them are extremely popular and analyzed by researchers quite often, some of them are left behind the topic. Some inventory management models focus on order planning techniques, others on responsibilities of order placement or stock allocation among warehouses. The traditional inventory management model between seller and buyer is called a two-tier model and is the simplest order placement way. It tells which party has the right to manage inventory and fulfil stock under agreed terms and conditions. Based on the roles, these methods are classified and help to improve the availability of the products, increase sales, and freshness with the lowest possible level of inventory throughout the supply chain and costs. A review of models will be presented seeking to extend the knowledge about inventory management in the supply chain. A revision is combined with the empirical part, under which by analyzing educational tool and its application in students' classes some interesting results were gathered. Further, the methods covering the learning of the inventory management process is compared, and a new learning approach is proposed. Finally, findings, limitations, and future research directions are presented at the end of the paper.
\end{abstract}

Keywords: Supply chain, inventory management, order placement, learning approach, educational tool 


\section{Introduction}

There are many literature sources on inventory management as the role of inventory is becoming increasingly important in today's competitive market. Efficient supply chains or networks compete successfully in the global market. Finally, the race for a lower price dictates reducing stocks as much as possible. On the other hand, such reduce service levels and increases the level of lost sales and costs.

The best way to present the supply chain is to show students the effect of coordination and collaboration with chain partners, which can be suppliers, wholesalers, retailers, and customers. Such stimulates active learning process, and the knowledge is absorbed faster than using standard multimedia materials (slides, video, books, etc.).

In summary, the complex inventory management process must be presented in the easiest way that gives students an understanding of how inventory management works in the supply chain and allows to learn from their mistakes during the practical training.

\section{Inventory Management Models in Supply Chain}

Four inventory management models define the roles of buyer and seller. In supply chain management the most often is used BMI model, according to which the buyer orders products from the seller. The buyer is placing an order to the seller following up-to-date sales information. By placing the order buyer must meet minimum order quantity requirements, which sometimes mean full loads but not always.

The second inventory management model is VMI, according to which the seller (vendor) decides on order quantity by using sales data from the buyer and places the order on behalf of the buyer.

As for the stock management models, the following four models can be considered:

- BMI (Buyer Managed Inventory): model mostly used in the replenishment process, in which the customer has stock control and plans his purchases.

- VMI (Vendor Managed Inventory): Orders are processed by suppliers without the customer having to approve the order, as is the case with VRI. The difference lies in the fact that in the (purely) VMI model, orders require more planning, namely for certain areas or seasonal periods.

- CMI (Co-Managed Inventory): the supplier sends an order proposal with defined quantities for each of the products. The final decision is up to the customer as he will have to approve the order or not.

- VRI (Vendor Replenished Inventory): orders are processed by suppliers, without the customer having to approve the order.

Despite the existence of these models, it is common to designate the CMI and VRI models with the term VMI, since the supplier is responsible for the supply process. 
In the VMI model case, the system focuses on a strategic decision in which the majority of departments in the organization (logistics, planning, sales, and marketing) is involved. It is, therefore, necessary to use a holistic approach to strategy, products, and communication. Cooperation is the main success factor for the usage of the VMI model. Buyers and sellers must enter the VMI for multidisciplinary work teams to collaborate, understand the needs and requirements of partners and search for "win-win" solutions together.

In the case of VMI, buyers usually define products range and plan-o-grams and allow the sellers to be responsible for stock replenish. Some VMI scenarios are even running further: buyers allocate shelf space and allow manufacturers to plan the product range and fulfil shelves without additional quantities. This is the main outcome for VMI manufacturers to control all marketing decisions at the points of sale.

During empirical research, the author will investigate the VMI model and present outcomes of what is covered under the Beer game simulation tool that is used for students active learning.

\section{Methods Used for Learning: Active and Passive}

Several methods are used during the learning process. Active learning techniques are based on a query-response mechanism. They interact iteratively with the operating system, sending inputs (requests) and monitoring outputs (responses) and concludes on hypothetical models based on interactions. Such a method guarantees the revision of the behaviour of supply chain partners which act according to the assumption that counterexamples distinguish a hypothetical model of the system can be found during the inventory management experiments.

However, the number of test sequences required is growing exponentially depending on the number of supply chain partners. The performance of such a large set of tests sequences are very time consuming but reflects the full behaviour of the operating system. Hence, the application of active learning in practice leads to trade-offs effectiveness and coverage of behaviour.

Passive learning methods conclude models from the set of execution logs. Because they meet the limited number of uses, learning outcomes are also available in a limited way. In addition, these methods introduce overestimation, making it difficult to learn complete system behaviour.

The comparison of active and passive learning is provided in Table 1 below. 
Table 1: Comparison of active and passive learning

\begin{tabular}{|c|c|l|}
\hline Learning type & \multicolumn{2}{|c|}{ Analytical category } \\
\hline \multirow{5}{*}{ Active } & Action-based & The behaviour of supply chain partners \\
\cline { 2 - 3 } & The level of analysis & Two-echelon function \\
\cline { 2 - 3 } & Process & $\begin{array}{l}\text { Demand management, Stock Management, } \\
\text { Order placement, Order Delivery }\end{array}$ \\
\cline { 2 - 3 } & $\begin{array}{c}\text { Process and supply } \\
\text { chain modelling }\end{array}$ & System Dynamics \\
\cline { 2 - 3 } & $\begin{array}{c}\text { The modelling } \\
\text { techniques }\end{array}$ & $\begin{array}{l}\text { Queuing modelling, Simulation of System } \\
\text { Dynamics }\end{array}$ \\
\hline \multirow{4}{*}{ Passive } & $\begin{array}{c}\text { The purpose of the } \\
\text { method }\end{array}$ & Descriptive \\
\cline { 2 - 3 } & The type of model & $\begin{array}{l}\text { An analytical or mathematical programming } \\
\text { model }\end{array}$ \\
\hline
\end{tabular}

Presented learning methods are adopted to cover supply chain modelling, which is investigated to include aspects of inventory management. For Table 1 active learning method is pre-dominant comparing to the passive learning method, as covers much more analytical categories which are presented for students in a more detailed way.

\section{Learning Approach}

A large gap exists between theory and practice talking about the complexity of inventory management. Due to that, it is good to present to students how the system works, and stock is managed by applying the classic 'BeerGame' simulation tool, which represents the BMI model.

In Table 2 there are presented references that analyze stock management and delivery processes in the supply chain.

Table 2: The application of supply chain processes

\begin{tabular}{|l|l|l|}
\hline Processes & \multicolumn{1}{|c|}{ Stock management } & \multicolumn{1}{c|}{ Order delivery } \\
\hline Authors & Devika et al. 2016; Gao et al. & Ahmadizar et al. 2015; Cai et al. 2015; \\
& 2013; Jun et al. 2015; Kuo 2001; & Karakatic et al. 2015; Kumar et al. 2014; \\
& Lawrence et al. 2002; Zhang et al. & Liu et al. 2014; Mohr 2014; Pierre et al. \\
& 2014 & 2014; Psychas et al. 2015; Zhang et al. \\
& & 2014 \\
\hline
\end{tabular}

According to the papers, it is difficult to represent how the system works for beginning practitioners. The learning approach involves action-based learning through simulation.

Simulation of events, processes, or pattern of things that are or may exist is presented by Feldman (1995). There are a lot of different models, which can be widely used. Visual models can give better graphical representation (Magee, 2006). A model is used for simulation that is different from those of other dynamics. By simulating the operation of the system model displays and allows to monitor 
changes depending on various parameters at a single point of time (Magee, 2006), to construct a situation that reflects the everyday problems, constraints, and resources (Jiwa et al, 2004).

Authors also use games and simulations to evaluate the effectiveness of different attempts (Taylor et al., 1972, Wolfe et al., 1998; Feinstein, 2001; Bagdonas, 2002). The mentioned authors indicate different attributes of the simulation, but most of them agree that imitation should reflect the real situation and to be active, dynamic.

According to Magee (2006), the simulation demonstrates its benefits:

-The risk-free environment. Solutions developed in a way that does not have consequences. Experimentation. Students involved in experimentation can change both their behaviour and the model parameters and monitor the resulting changes in the simulation system;

-Problem-solving. Simulators allow to deal with problem situations and take responsibility for the consequences of decisions made;

-Evaluation. Visible consequences of the decisions made.

- Other authors (Taylor et al, 1972) points out the features of the simulation:

-Simulation technique encourages activities that are representative of a generalized approach to the situation;

-Simulation is usually based on the problem;

This technique is dynamic. The simulated situation is changing, adapting to circumstances.

Taylor et al. (1972) identified three main types of simulation: role-playing game simulation, and computer simulation.

Several authors (Thompson et al., 1997; Jenning, 2002; Bagdonas, 2002; Adobor, 2006) is discussing the advantages and disadvantages of imitation. Simulation provides the benefit on a variety of perspectives:

-First, imitation helps to make strategic decisions in applying the principles that have been theoretically analyzed.

-Second, compared with the traditional case analysis, simulation can be the better method of analysis (Jennings 2002). However, the simulation must be realistic.

A behavioural simulation forces students to act on the supply chain situation. The circumstances may be related to a business situation, or to support other environments. Situations are cognitive (cognitive) going on to understand the key business events, facts and concepts in a way that can make decisions. Later cognitive skills are required to transform the simulation results into the right decisions and strategies.

While the tradition of simulation is old in the world, in Lithuania the method is introduced relatively recently. Business simulation games in Lithuania are examined by Bagdonas (2002), and others. Čiegis (2005) are analyzing simulationbased business games. Bagdonas (2002) analyzed the computerized business games, 
methodological and practical aspects of the recovery, with a focus on enterprisewide, rather than individual features during games. Still, among named works, there is a lack of attention for simulation models used in the supply chain.

The simulation model used to analyze real situations is well-known as the timehorizon models. Many factors can be incorporated in time models, such as order placement, order fulfilment, order delivery in the supply chain. Some time models estimate the time required to complete tasks (Cormier 2005). Finally, results of the performance during the time horizon period are analyzed seeking to minimize the influence of inefficiency that is represented as costs of all supply chain partners and for each of them individually.

The beer game makes it possible to understand the problems in the supply chain in the absence of coordination, systematic thinking and planning. The game reveals the benefits of information sharing, supply chain management, collaboration for business.

\section{Methodology and Empiric Research}

Six students' groups applied the Beer game tool for inventory management. Each group consisted of four players in different roles: producer (manufacturer), distributor, wholesaler, and retailer.

Each actor in the supply chain could manage only part of its supply chain, but its actions, it can have a significant impact on the entire supply chain by ordering too many or too few goods. Manufacturers, suppliers, vendors, and customers often have a perception of what real demand is. The start of demand depends on a buyer whose purchase is often difficult to predict.

For each group, the planning horizon for demand was 20 weeks. In total students generated 120 data sets. Each data sets included information about current stock, backlog (not fulfilled demand), placed order, current demand, and calculated costs. The costs for having backlog is penalized by 50 Eur and the costs for having overstock - 20 Eur.

The correlation revision was used to revise results and the number of periods after which the effect is evident.

All data sets converted to logarithmic values (DLOG) and correlation is provided for them. The distributor profile is presented below in Table 3. It shows the impact of distributor backlog to other distributor logarithmic data sets. 
Table 3: The distributor profile

\begin{tabular}{|l|l|r|r|r|}
\hline \multicolumn{2}{|c|}{ Elements of statistical analysis } & DLOG(DB) & DLOG(DC) & DLOG(DC(-2)) \\
\hline \multirow{2}{*}{ DLOG(DC) } & Correlation coefficient & 0,53 & 1 & \\
\cline { 2 - 5 } & Probability & $\mathbf{0 , 0 1}$ & ----- & \\
\hline \multirow{2}{*}{ DLOG(DD) } & Correlation coefficient & 0,48 & 0,22 & 0,24 \\
\cline { 2 - 5 } & Probability & $\mathbf{0 , 0 2}$ & 0,29 & 0,26 \\
\hline \multirow{2}{*}{ DLOG(DD(-1)) } & Correlation coefficient & 0,18 & 0,49 & $-0,09$ \\
\cline { 2 - 5 } & Probability & 0,40 & $\mathbf{0 , 0 1}$ & 0,65 \\
\hline \multirow{2}{*}{ DLOG(DD(-2)) } & Correlation coefficient & 0,43 & 0,06 & $-0,17$ \\
\cline { 2 - 5 } & Probability & $\mathbf{0 , 0 3}$ & 0,76 & 0,41 \\
\hline \multirow{2}{*}{ DLOG(DO) } & Correlation coefficient & 0,02 & $-0,08$ & 0,41 \\
\cline { 2 - 5 } & Probability & 0,89 & 0,70 & $\mathbf{0 , 0 4}$ \\
\hline
\end{tabular}

Herein: DB - Distributor backlog, DO - Distributor order, DD - Distributor demand, DC - Distributor costs

The backlog of the distributor affects its costs, order, and demand of the current period and on-demand of two in the row upcoming periods. This relationship could be explained as the backlog hurting costs.

Table 4: The manufacturer profile

\begin{tabular}{|l|l|l|l|l|}
\hline \multicolumn{2}{|l|}{ Elements of statistical analysis } & DLOG(DB) & DLOG(MB) & DLOG(MB(-1)) \\
\hline \multirow{2}{*}{ DLOG(MB(-1)) } & Correlation coefficient & $-0,92$ & $-0,70$ & 1 \\
\cline { 2 - 5 } & Probability & 0,02 & 0,18 & ----- \\
\hline \multirow{2}{*}{ DLOG(MB(-2)) } & Correlation coefficient & 0,93 & 0,79 & $-0,78$ \\
\cline { 2 - 5 } & Probability & 0,02 & 0,10 & 0,11 \\
\hline \multirow{2}{*}{ DLOG(MC) } & Correlation coefficient & 0,60 & 0,91 & $-0,63$ \\
\cline { 2 - 5 } & Probability & 0,28 & 0,02 & 0,24 \\
\hline \multirow{2}{*}{ DLOG(MC(-2)) } & Correlation coefficient & 0,84 & 0,28 & $-0,71$ \\
\cline { 2 - 5 } & Probability & 0,07 & 0,64 & 0,17 \\
\hline \multirow{2}{*}{ DLOG(MD(-1)) } & Correlation coefficient & 0,93 & 0,72 & $-0,9$ \\
\cline { 2 - 5 } & Probability & 0,01 & 0,16 & 0,00 \\
\cline { 2 - 5 } & Probability & $-0,87$ & $-0,42$ & 0,90 \\
\hline \multirow{2}{*}{ DLOG(MD(-2)) } & Correlation coefficient & 0,85 & 0,47 & 0,03 \\
\cline { 2 - 5 } & Probability & 0,06 & 0,42 & $-0,76$ \\
\hline
\end{tabular}

Herein: MB - Manufacturer backlog, MD - Manufacturer demand, MC - Manufacturer costs

The backlog of the distributor harms the manufacturer's backlog and demand for the upcoming period. The relationship is explained because the distributor to compensate backlog place the order to manufacturer the same period when backlog appears. 
From Table 4, we see that manufacturer reacts to distributor backlog in the first or the second upcoming period.

Table 5: The wholesaler profile

\begin{tabular}{|c|l|c|c|}
\hline \multicolumn{2}{|c|}{ Elements of statistical analysis } & DLOG(DB) & DLOG(WD) \\
\hline \multirow{2}{*}{ DLOG(WD) } & Correlation coefficient & $-0,83$ & 1 \\
\cline { 2 - 4 } & Probability & 0,0 & ---- \\
\hline \multirow{2}{*}{ DLOG(WO(-1)) } & Correlation coefficient & 0,57 & $-0,66$ \\
\cline { 2 - 4 } & Probability & 0,08 & 0,03 \\
\hline \multirow{2}{*}{ DLOG(WO(-2)) } & Correlation coefficient & 0,03 & 0,19 \\
\cline { 2 - 4 } & Probability & 0,91 & 0,59 \\
\hline \multirow{2}{*}{ DLOG(WO(-3)) } & Correlation coefficient & 0,73 & $-0,70$ \\
\cline { 2 - 4 } & Probability & 0,01 & 0,02 \\
\hline
\end{tabular}

Herein: WO - Wholesaler order, WD - Wholesaler demand

The backlog of the distributor has a link with wholesaler demand and order in several periods. The link with wholesaler demand is negative.

Table 6 - The retailer profile

\begin{tabular}{|c|l|c|c|c|}
\hline \multicolumn{2}{|c|}{ Elements of statistical analysis } & DLOG(DB) & DLOG(RC) & DLOG(RC(-3)) \\
\hline \multirow{2}{*}{ DLOG(RC) } & Correlation coefficient & 0,38 & 1 & \\
\cline { 2 - 5 } & Probability & 0,04 & ----- & \\
\hline \multirow{2}{*}{ DLOG(RC(-3)) } & Correlation coefficient & 0,44 & & \\
\cline { 2 - 5 } & Probability & 0,01 & & \\
\hline \multirow{2}{*}{ DLOG(RD(-1)) } & Correlation coefficient & $-0,26$ & $-0,55$ & $-0,33$ \\
\cline { 2 - 5 } & Probability & 0,18 & 0,00 & 0,08 \\
\hline \multirow{2}{*}{ DLOG(RD(-2)) } & Correlation coefficient & 0,34 & 0,01 & 0,60 \\
\cline { 2 - 5 } & Probability & 0,08 & 0,95 & 0,00 \\
\hline
\end{tabular}

Herein: $R C$ - Retailer costs, $R D$ - Retailer demand

The link between distributor backlog, retail costs and demand exists and is evident in three periods, because the lead-time between order and delivery is 2 weeks.

Overall, there are clear relationships in various time periods, which represent additional system behaviour aspects evident in different roles in the supply chain.

\section{Concluding Remarks}

The inventory management topic is quite old, however, there is a lack of literature about four inventory management models to which attention was given in this paper. 
The author also taught the topic about learning which is especially important for students, seeking practical knowledge about inventory management and behaviour about supply chain partners in their role fulfilment. In the paper, the author compared active and passive learning and concluded that active learning is highly recommended for learning complex things and concepts. In the paper also learning approach via simulation was investigated and presented by demonstrating the benefits of active learning tool, one of which is the simulation technique.

The empirical research defines links that are important during inventory management. And it presents more additional information, which could be included in the demonstration of the Beer game tool as supportive data which clarify more deeply the inventory management process.

The author presented four profiles in empirical research: the profiles of the manufacturer, distributor, wholesaler, and retailer and links between their actions in demand planning, order placing, costs minimization. The research has some limitations: only a backlog of the distributor was investigated by leaving other analytical elements behind. In future studies, many other relationships could be investigated and presented.

\section{References}

Adobor, H. (2006). Management simulations: Determining their effectiveness. Journal of Management Development, 25(2), 151-168.

Ahmadizar F, Zeynivand M \& Arkat J (2015). Two-level vehicle routing with cross-docking in a three-echelon supply chain: A genetic algorithm approach. Applied Mathematical Modelling, 39 (22), 7065-7081.

Alfieri, A. and Zotteri, G. (2017). Inventory theory and the Beer Game, International Journal of Logistics Research and Applications, 20(4), 381-404.

Bagdonas, E. (2002). Verslo žaidimai: samprata, modeliai, tikrovė [Business games: perception, models, reality]. Kaunas: Technologija.

Cai, Y. G., Tang, Y. L. \& Yang, Q. J. (2015). An improved genetic algorithm for multi-depot heterogeneous vehicle routing problem with simultaneous pickup \& delivery time windows. Applied Mechanical Material, 738, 361-365.

Claassen, M. J. T., Van Weele, A. J. \& Van Raaij, E. M.(2008). Performance outcomes and success factors of vendor managed inventory (VMI), Supply Chain Manag. An International Journal, 13(6), 406-414. 
Cormier, G. 2005. Operational research methods for efficient warehousing, Langevin, A.; Riopel, D. (Ed.), Logistics systems: design and optimization, Springer Verlag, 93-122.

Čiegis, R., Skunčikienè, S., Rakickas, A. 2005. Verslo žaidimų samprata ir paskirtis žinių visuomeneje [The concept and purpose of business games in the knowledge society], Organizaciju vadyba: sisteminiai tyrimai, 35.

Devika, K., Jafarian, A., Hassanzadeh, A., \& Khodaverdi, R. (2016). Optimising of bullwhip effect \& net stock amplification in three-echelon supply chains using evolutionary multi-objective metaheuristics. Annals of Operations Research, 242 (2), 457-487.

Feinstein, A. H., Cannon, H. M. 2002. Constructs of Simulation Evaluation. Simulation and Gaming.

Gao, L., Xu, K. L. \& Mao, D. X. (2013). Research of sales forecasting model \& algorithm in food \& beverage enterprise. In: The 19th International Conference on Industrial Engineering \& Engineering Management, 925-934. Berlin: Springer.

Hammer, H. and Bernasconi, C. Best Practice in Implementing VMI A recommendation by ECR Europe, 2016. [Online]. Available: https://www.gs1.ch/docs/default-source/prozesse-dokus/ecr-community---bestpractice-in-implementing-vmi.pdf?sfvrsn=2. [Accessed: 02-Oct-2017].

Jennings D. (2002). Strategic management: an evaluation of the use of three learning methods. Journal of Management Development, 21(3/10), 655-665.

Jiwa, S., Lavelle, D., Rose, A. (2004). Netrepreneur simulation: enterprise creation for the online economy. International Journal of Retail \& Distribution Management. 32(12), 587-596.

Jun, T. \& Qing, W. (2015). Optimise BP neural network structure on car sales forecasts based on genetic algorithm. In: International Industrial Informatics \& Computer Engineering Conference, 75-79. Atlantis Press.

Karakatic, S. \& Podgorelec, V. (2015). A survey of genetic algorithms for solving multi depot vehicle routing problem. Applied Soft Computer, 27, 519-532.

Kumar, V. S., Thansekhar, M. R., Saravanan, R. \& Amali, S. M. J. (2014). Solving multi-objective vehicle routing problem with time windows by FAGA. Proceedings Engineering, 97, 2176-2185. 
Kuo, R. J. (2001). A sales forecasting system based on fuzzy neural network with initial weights generated by genetic algorithm. European Journal of Operational Research, 129 (3), 496-517.

Lawrence, J. A. \& Pasternack, B. A. (2002). Applied management science: Modelling, spreadsheet analysis, \& communication for decision making, 2nd ed. New Jersey: Wiley

Liu, R., Jiang, Z \& Geng, N. (2014). A hybrid genetic algorithm for the multi-depot open vehicle routing problem. OR Spectrum, 36 (2), 401-421.

Lotfi, Z., Mukhtar, M., Sahran, S. and Zadeh, A. T. (2013). Information Sharing in Supply Chain Management, Procedia Technology, 11, 298-304.

Madhusudanan, P., Pamulety, T. C. and Pratap, V. E. (2014). Performance Analysis of Some Supply Chain Replenishment Strategies. International Journal of Logistics Research and Applications, 17 (5), 357-376.

Magee, M. 2006. State of Field Review: Simulation in Education. Final Report.

Mohr, C. M. (2014). Optimisation of warehouse order-picking routes using vehicle routing model \& genetic algorithm. Doctoral dissertation, State University of New York at Binghamton.

Nooraie, M. (2012). Factors Influencing Strategic Decision-Making Processes. International Journal of Academic Research in Business and Social Sciences, 2 (7): 405-429.

Pierre, D. M. \& Zakaria, N. (2014). Partially optimised cyclic shift crossover for multi-objective genetic algorithms for the multi-objective vehicle routing problem with timewindows. In: 2014 IEEE Symposium on Computational Intelligence in Multi-Criteria Decision-Making, 106-115.

Prajogo, D. and Olhager, J. (2012) Supply chain integration and performance: The effects of long-term relationships, information technology and sharing, and logistics integration, International Journal of Production Economy, 135(1), 514-522.

Psychas, I. D., Marinaki, M. \& Marinakis, Y. (2015). A parallel multi-start NSGA II algorithm for multiobjective energy reduction vehicle routing problem. In: International Conference on Evolutionary Multi-Criterion Optimization, 336-350. Springer International Publishing. 
Su, Y., and Geunes, J. 2012. Price Promotions, Operations Cost, and Profit in a Two-stage Supply Chain. Omega, 40(6), 891-905.

Sue Stewart Wingfield \& Gregory S. Black (2005), Active Versus Passive Course Designs: The Impact on Student Outcomes, Journal of Education for Business, 81(2), 119-123.

Taylor, J., Walford, R. 1972. Simulation in the Classroom. Great Britain: Nichols. C. \& Company Ltd.

Thompson, T. A., Purdy, J. M., \& Fondt, P. M. (1997). Building a Strong Foundation: Using a Computer Simulation in a Introductory Management Cource, Journal of Management Education, 21(3).

Trapero, J. R., Kourentzes, N. \& Fildes. R. (2012). Impact of Information Exchange on Supplier Forecasting Performance. Omega, 40 (6), 738-747.

Wei-Hsi, H., L. H., Chin-Fu, J., Jau-Jeng \& Yi-Ming, T. (2011). Sharing Information Strategically in a Supply Chain: Antecedents, Content and Impact. International Journal of Logistics Research and Applications, 14 (2), 111-133.

Wolfe, J. 1998. New Developments in the Use of Simulations and Games for Learning. Journal of Workplace Learning.

Zhang, J. \& Li, J. (2014). A hybrid genetic algorithm to the vehicle routing problem with fuzzy cost coefficients. In: 2014 IEEE 11th International Conference on Fuzzy Systems \& Knowledge Discovery, 147-152.

Zhang, S. \& Qinghe, H. (2014). Application of GA optimising neural network to coal sales forecasts. In: 2nd International Conference on Information, Electronics \& Computer. Atlantis Press. 